preparations of wheat, rather than oat-meal, which will frequently be observed to increase an eruption. Bread made from whole wheat flour should be encouraged, eaten with plenty of butter, which improves these cases, especially if they are under an alkali medication. Meat juice may also be given in moderation, but care should be exercised that it is not taken in excess, as there is danger of over stimulation, and I have repeatedly seen bad results from excessive use of beef-tea and animal food in these cases.

As the teeth are formed the diet must of course be more varied and more freedom must be given, and parents will often think children ill-nourished if they are not allowed a great variety, indeed if they do not take the food of adults. But the prodigious mortality from bowel troubles among children under 5 years of age reminds us that much knowledge is yet needed before those having the care of the young shall rightly attend to the diet. If life can be thus endangered, the same or other errors in lesser degree must affect the state of the child both in health and disease.

I will not take time to discuss more fully our interesting subject, or to enter upon more details in regard to the many possible matters in regard to diet which might be spoken of-they could readily fill a large book. Enough has been said to introduce the topic for discussion and to present the points which experience has shown me to be of importance in connection with our subject; briefly mentioned these are as follows :

I. The necessity of carefully watching the diet of infants with eczema, and giving special instructions that harmful articles may be avoided.

2. Specific instructions in regard to food and its preparation for these cases.

3. The more free use of milk, both for nursing mothers and for infants deprived of breast milk.

4. The taking of milk by adults apart from all $B$. other food in the interval before meals, when an alkaline state of the stomach facilitates its immediate aksorption.

5. The more free employment of wheat products in the nourishment of older children with infantile eczema.

\section{SCIENTIFIC COLLECTIVE INVESTIGATION OF DISEASE.}

Read in Section on State Medicine, at the Thirty-Eighth Annual Meeting of the American Medical Association, Fune, 1887

BY HENRY B. BAKER, M.D., of LANSING, Michigan.

The purpose of this paper is to suggest how "collective investigation of disease" may be put upon a more scientific basis than is usually attempted, to urge the importance of such scientific investigations, and to point out how they may be equitably maintained, through the coöperation of physicians and governments. A few illustrations of what has already been accomplished will also be mentioned.

The term "Collective Investigation of Disease" has been employed by the British Medical Association to designate a method of investigation inaugurated by that Association in I 88r, but urged by Dr. Arthur Ransom in a paper before that Association in I864. The movement was favored by Professor Humphry, Sir William Gull, Sir James Paget and others. Referring to the first number of the "Collective Investigation Record," Dr. William Roberts said: "No one can read it attentively without acquiring a feeling almost amounting to a conviction that the movement is one of real importance, and that it will result in a large addition to our knowledge that could not have been got in any other way." Mr. Jonathan Hutchinson, has said: "Permit me to say then, that I cannot for a moment doubt that our distinguished associate, Professor Humphry, when he persuaded our Association to organize the large scheme which we are here this afternoon to promote, has done that which will prove of great and lasting advantage to medical and surgical science. It is a scheme which deserves from us all the best help that we can give it. ${ }^{2}$ "

It is usually claimed that one of the chief objects for which medical societies are organized is the promotion and advancement of the medical sciences. The building up of an exact medical science cannot go on, with the greatest success, except through the collection of vast numbers of facts bearing upon each of the nurnerous questions involved, and the union of those facts by methods which will admit of numerical expression. General laws are reached only through such measures. Detailed histories of "interesting cases" of rare diseases, like the beautiful flowers along the pathway of the professional botanist, may serve as agreeable intellectual or emotional stimuli; but for the upbuilding of the medical sciences, we need the systematic collection and comparison of the most ordinary facts, and I think we must all agree with the Editor of the British Medical Journal when he says: "The chief aim of collective investigation, as applied to the main body of the profession, should be to collect simple everyday facts that can be easily observed and recorded, and which are of value only from their number, and not from the importance of individual observations."

There would seem to be no question that those diseases which are most common are the diseases which it is of most importance to study, for the purpose of learning their causes and how they may be prevented, avoided or treated. This being granted, it is proper to inquire whether the medical profession should not ask the coöperation of the whole people in promoting those medical sciences which tend directly to the amelioration of the physical condition of mankind. Leaving out of the question the subject of the treatment of disease, and confining it strictly to the subjects of the causation and best means of prevention of sickness, it would seem evident that the people as a whole should have much greater interests than the physicians have, and

1 Brit. Med. Jour., Nov 3, 1883, p. 860 ,

2 Brit. Med. Jour., Nov. 3, 1883, p. 862

3 Brit. Med. Jour., July 7, 1883, p. 20. 
should, not only coöperate, but should supply the greater portion of the pecuniary means for such investigations. To a limited extent this is now done in one State (Michigan), and in my opinion the best interests of all will be subserved when it is done in every State in the Union, and by all Governments throughout the civilized world.

How can this be done? Perhaps as suggestive an answer as I can give will be to state how one line of such investigation is done in Michigan. In Michigan the State Board of Health supplies to physicians in different parts of the State printed blanks on postal cards addressed to the office of the Board. The blanks contain a list of the most common and most important diseases. After the close of each week each observer fills out and sends to the central office a report of the sickness under his own observation as a practitioner. The investigation thus far has been limited to the question of the presence or prevalence of each of the important diseases; and it is so planned and compiled as to give this information quantitatively by months. (It would give it by weeks if sufficient work were put into the compilation to make it show for weeks instead of by months.)

The times of greatest and of least prevalence of each disease being learned in this manner, a similar method of investigation relative to the principal meteorological conditions which prevail is carried on by means of observers in different parts of the State, who take and record tri-daily observations, and report them to the office of the State Board of Health. Tables are constructed showing the relations of each important disease to each of the important meteoro. logical conditions; and diagrams accurately drawn to scale still more plainly show what those relations are. For instance, I show you a diagram exhibiting by months the relations which sickness from pneumonia bears to the atmospheric temperature, the diagram giving the averages of over 150,000 observations of the temperature, and of over $30, c 00$ weekly reports by physicians. Of that which was contributed by the physicians who took part in this investigation, that which has been used from the report each week, was the fact whether the physician did or did not see a case of the disease in question. The State Board of Health supplied the blanks, the postage, and the compilation of the whole in connection with the meteorological data similarly collected and compiled. The results when published are sent to each observer, but they are published as the common property of the world. It seems that by this method we are able to learn the times of greatest and of least danger from each important disease ; soon we should be able to see exactly what relation each meteorological condition bears to each important disease. If these investigations shall be carried on in different States and countries, we ought soon to be able to learn whether the meteorological conditions bear the same relations in all countries, or whether local conditions modify the results, and how they are modified. It may be practicable to extend the scope of such investigations by governmental coöperation. But at any rate, such coöperation as is now in force in Michigan, will make it pos-

sible for medical associations to direct their energies to investigations into results of different modes of treatment of diseases, and in therapeutic and other directions so as to supplement those investigations, as to causes and prevention, which it is manifestly the duty of Governments to maintain.

PROMPT REPORTS NEEDED.

For the most accurate recording of facts which shall serve as the basis for the sciertific investigation of disease, it is important that the record be made as near as possible to the time of occurrence of the phenomena recorded. Otherwise the record is likely to be molded in the direction of preconceived views held by the recorder, because his attention will be attracted to certain phenomena, and he will lose sight of, or sooner forget certain other phenomena. In Michigan it took several years to learn how much better weekly reports are than annual reports, for the purpose of studying the prevalence of any given disease. In April, I 876, the Michigan Board of Health issued a circular (somewhat like those since used by the Collective Investigation Committee) relative to scarlet fever, and collected facts of value, some of them relating to observations through many years; but on some points more precise information was desired. For several years a circular was issued at the close of every year, asking for facts which had been observed during the year just passed. But this method also was open to the objections which have been suggested.

In September, 1876 , the Michigan Board of Health inaugurated a system of weekly reports of sickness, copying somewhat after the plan which for a single year was followed in Massachusetts. ${ }^{4}$ At first the plan (in Michigan) was defective in that the reports were designed to give the observers best knowledge and belief relative to the sickness in his vicinity, and he was not directed to confine his reports strictly to the cases under his own observation. There was then an idea that a great proportion of the sickness in a locality might be reported with approximate accuracy by one of the several physicians in that locality. The present plan is based upon the belief that an accurate report of just what was seen by the reporter supplies much more useful facts for scientific study; and that an average practitioner in active general practice, will "in the long run," see an average of the cases of diseases which most frequently occur. The present plan supplies the facts, and they are reported within a week after their occurrence. It seems to me that this is Scientific Collective Investigation of Disease, and that it is an important work which should be entered upon by all State Boards of Health, and by a National Board of Health, and that physicians should seek to coöperate so far as practicable in such investigations. SICKNESS REPORTS AS SANITARY NEWS.

I respectfully submit that the weekly or monthly records of deaths, which are now usually published

4 I believe that a similar system was carried on in England for a short time about the year 1857 , and that an unsuccessful effort to have the Government adopt and pay for its continuance, was followed by its abandonment as too expensive for private enterprise, by the physicians who had perfected it. 


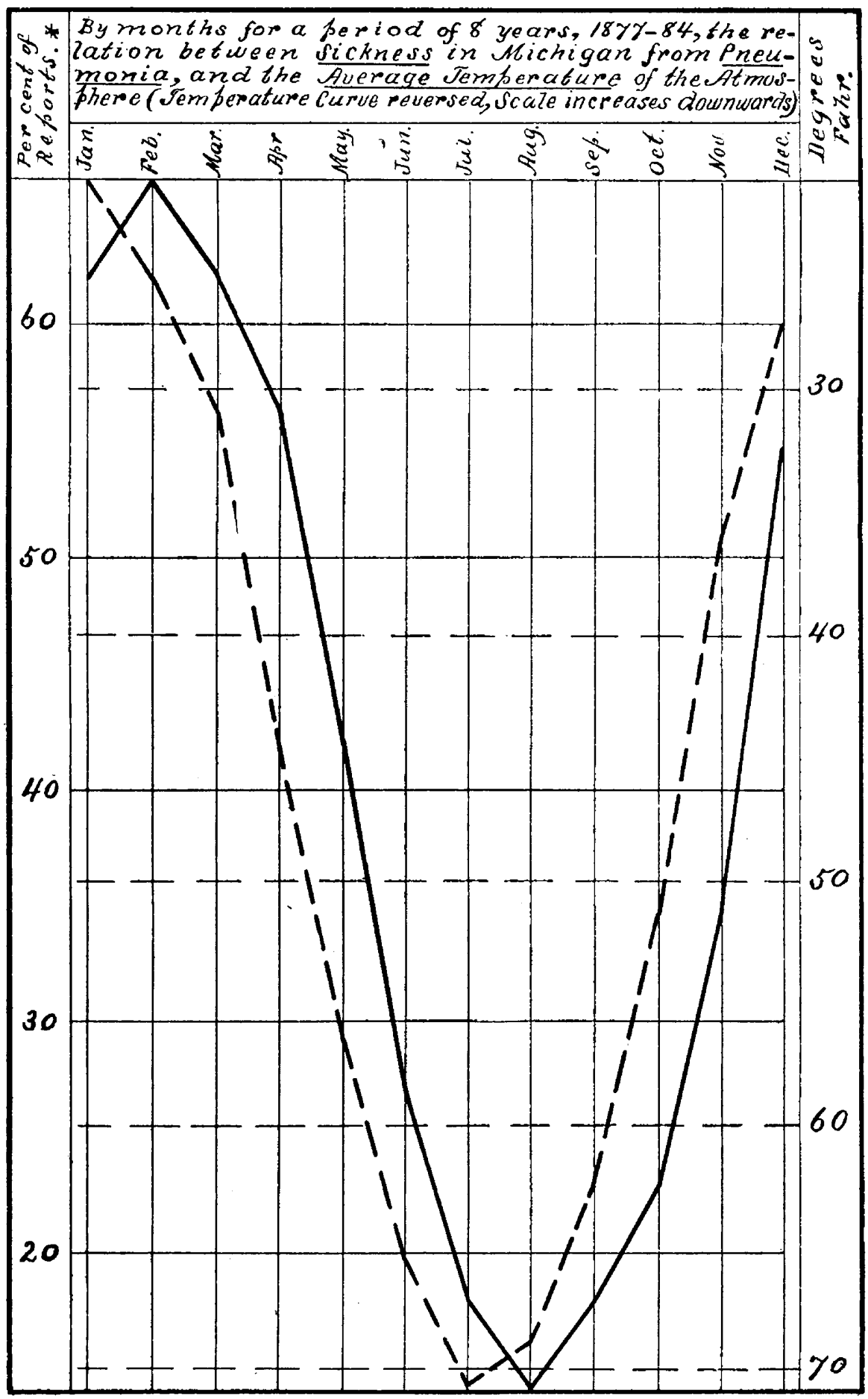

Sictness from Pneumonia _. Average Temperature - -. * Indicating what fer cent of all reports received, stated the preserce of preumonia then under the sbservalene of the physicians reporting.

over 30,000 weetly reports of siekness, and over 150,000 observations of the atmospheric temperature are reforeresented in this diagram. 
Diphtheria in Michigan in 1886, exhibsting the Auerage Numbers of Cases and Deaths ber outbreak:- (1) in All the 46) outbreaks Reported, (2) in the 243 outbreaks in which it is Doubtful whether or not Disinfection or 3 solation were secured, (3) in the 102 outbreaks in which Isolation or Disinfection or both were neg. lected, and (4) in the $/ 16$ outbreaks in which $g_{s o l a t i o n}$ and Visinfection were both enforced. (Compiled in the office of the Secretary of the state Board of Health from reports made by local health officers.)

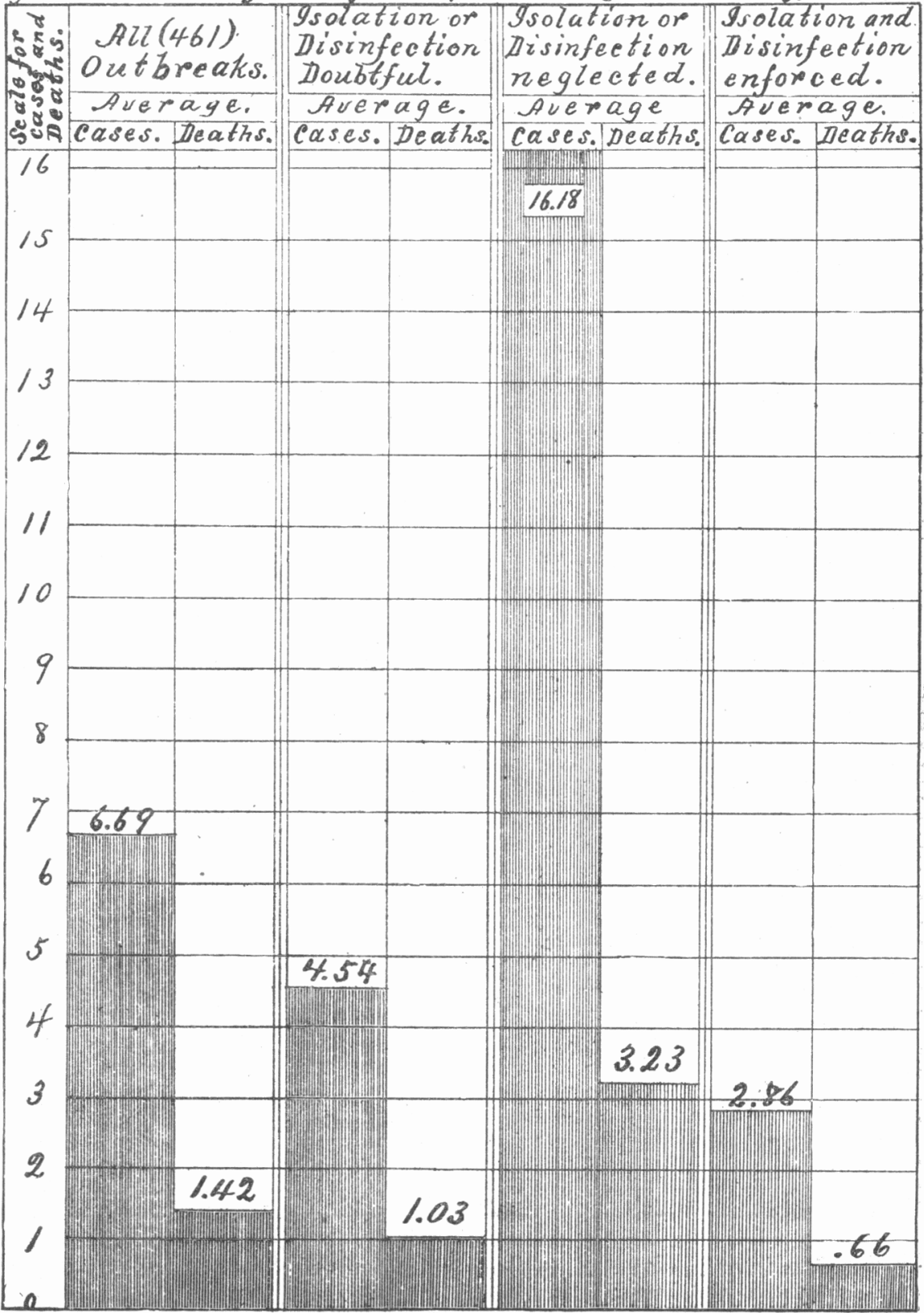


by boards of health as items of sanitary news, might well be displaced or supplemented by statements of the average sickness which has been observed during the week or month, as the case may be, and reported on this plan of collective investigation. There are two good reasons why it should be done:

I. There are diseases, which cause much sickness and consequent suffering and expense, which are not correspondingly represented in the mortality statistics. I think this may be appreciated by a study of the bulletin of sickness in Michigan in the month of May, 1887 , a copy of which I submit herewith, and from which it may be seen that neuralgia, bronchitis, and intermittent fever rank high as causes of sick. ness, while we all know that those diseases do not rank high as causes of death.

HEALTH IN MICHIGAN, MAY, 1887.

Reports to the State Board of Health, Lansing, by regular observers in different parts of the State. show the diseases which caused most sickness in Michigan during the month of May (four weeks ending May 28), 1887 , as follows:

\begin{tabular}{|c|c|c|}
\hline Number of Reports Receivfd, 22 I. & & $\begin{array}{l}\text { For preced- } \\
\text { ing month. }\end{array}$ \\
\hline $\begin{array}{c}\text { Diseases, Arranged in Order of Greatest } \\
\text { Prevalence. }\end{array}$ & $\begin{array}{l}\text { Per cent. of } \\
\text { reports stat- } \\
\text { ing presence } \\
\text { of disease. }\end{array}$ & $\begin{array}{l}\text { Per cent. of } \\
\text { reports stat- } \\
\text { ing presence } \\
\text { of disease. }\end{array}$ \\
\hline 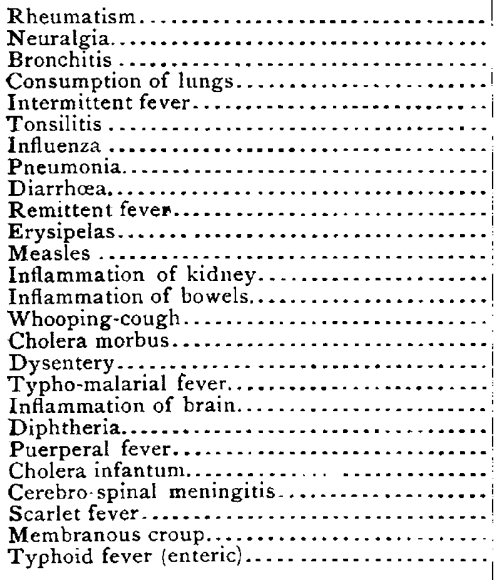 & $\begin{array}{l}71 \\
67 \\
57 \\
51 \\
49 \\
47 \\
35 \\
33 \\
30 \\
30 \\
29 \\
28 \\
19 \\
15 \\
13 \\
11 \\
9 \\
8 \\
7 \\
6 \\
5 \\
5 \\
5 \\
5 \\
4 \\
3\end{array}$ & $\begin{array}{r}79 \\
73 \\
64 \\
58 \\
52 \\
54 \\
43 \\
42 \\
30 \\
30 \\
28 \\
22 \\
22 \\
17 \\
11 \\
4 \\
7 \\
12 \\
4 \\
4 \\
7 \\
2 \\
2 \\
9 \\
6 \\
3\end{array}$ \\
\hline
\end{tabular}

For the month of May, $\mathrm{r} 887$, compared with the preceding month, the reports indicate that cholera morbus increased, and that pneumonia, influenza, rheumatism, bronchitis, consumption of lungs and tonsilitis decreased in prevalence.

Compared with the preceding month, the temperature in the month of May was much higher, the absolute humidity was much more, the relative humidity was about the same, the day and the night ozone were more

Compared with the average for the month of May in the nine years, I879-I887, intermittent fever, remittent fever, consumption of lungs, scarlet fever, diphtheria and diarrhœa were less prevalent in May, 1887.

For the month of May, 1887 , compared with the average of corresponding month for the nine years, $1879-1887$, the temperature was higher, the absolute humidity, the relative humidity, and the day ozone were more, and the night ozone was less.

Including reports by regular observers and others, diphtheria was reported present in Michigan in the month of May, I887, at thirty places, scarlet fever at thirty-two places, typhoid fever at four places, measles at fifty places.

Reports from all sources show diphtheria reported at five places more, scarlet fever at seven places less, typhoid fever at four places less, measles at fourteen places more, in the month of May, 1887 , than in the preceding month.

Lansing, June2, I 887 .
2. Records of deaths are very valuable for purposes of study, but as indications of existing dangers they are not as good as reports of sickness. After the deaths have occurred, have been reported, and published, the time has passed for best guarding against the diseases which caused the deaths. On the other hand, prompt reports of sickness enable a State Board of Health to aid local health officers in restricting dangerous communicable diseases; and the publication of the facts concerning such sickness would be of much greater value to the people of the locality and to the health officers who would receive the reports in exchange, than are the present reports of mortality statistics.

INVESTIGATION OF PRACTICAL RESULTS OF SANITARY WORK.

Collective investigation can be successfully applied to many other results than those of the different modes of treatment of diseases. For instance, I show a diagram exhibiting, graphically, the results of different modes of action with a dangerous disease of children, namely, diphtheria, the facts having been reported, immediately after the outbreak closed, by health officers, to the State Board of Health, not exactly in accordance with the plan of coöperation by government and physicians, which I have recommended in this paper, but nearly so, because as yet the health officers have too little compensation for such official reports to entitle the government to have credit for the entire work. The evidence, when compiled and graphically shown, seems to me to be of immense value as a guide to proper efforts for the prevention of sickness and deaths. The diagram shows that in 102 outbreaks of diphtheria in which isolation or disinfection, or both, were neglected, the average number of cases was 16.18 , and the average deaths were 3.23 , while in the 116 outbreaks in which isolation and disinfection were both enforced the average cases and deaths were only about one-fifth as many, indicating a saving of about three hundred lives and I, 545 cases of sickness from diphtheria. The inference is strong that if this was true of one or two hundred outbreaks of diphtheria in Michigan in 1886, it may be found to be true in other States and in other years, in which case the knowledge gained by the investigation ought to be of immense utility in guiding to the saving of human life and health.

\section{DISCUSSION.}

DR. H. C. Markham, of Independence, Iowa, thought this paper should give an impetus to our efforts at reporting.

DR. A. N. BELl, of New York, asked whether local conditions could not be included in Dr. Baker's charts. Many places of equal temperature would vary greatly in disease rate, on account of local conditions.

DR. J. M. Allen, of Iiberty, Mo., thought that the States fail to discharge their duty in the matter of providing means for these investigations. In the present instance, therefore, we owe the State of Michigan a vote of thanks (as well as Dr. Baker), for its action has been exceptional. 
Remarks were made by others, showing the extreme difficulty of influencing State legislators to act.

DR. BAKER said we must go slowly, but in time we can get at what Dr. Bell suggests. Money will be given more willingly when this work is also done in other States. Michigan has done well in this matter since 1876 . Massachusetts carried on the work one year and then dropped it.

\section{THE PROPRIETY AND NECESSITY OF STATE REG- ULATION OF MEDICAL PRACTICE.}

Read in the Section of State Medicine, at the Thirty. Eighth Annual Meeting of the American Medical Association, Fune, 1887 ,

BY PERRY H. MILLARD, M.D,

FIRST VICE-PRESIDENT AMERICAN MEDICAL ASSOCIATION, EX-PRESIDENT MINNESOTA STATE MEDICAL ASSOCIATION, SECRBTARY MINNESOTA STATE BOARD OF MEDICAL EXAMINERS.

In the year 1237 the college at Salino, which was founded early in the eleventh century, instituted a series of regulations to the effect that no one should practice physic who had not studied philosophy three years and physic five, and had obtained the license of the college after undergoing an examination at the end of such period. Very similar regulations were shortly thereafter adopted by the English universities, and the standard of medical knowledge and education was thereby considerably raised, and a great impetus given to the pursuit of medicine. The first degrees in medicine can be traced back to the year 1384 .

We find by comparison, that one hundred and fifty years before degrees or diplomas were granted, the universities licensed candidates to practice only after they had pursued philosophy three years and physic five, and that six hundred and fifty years thereafter, in 1887 , the requirements of 73 per cent of the schools of the United States require only two courses of lectures and three years' study. It would, however, be unfair for me to omit the startling fact that a certificate of good moral character is a sine qua non from all the schools of this country.

The first law regulating the practice of physic in the United Kingdom was enacted in I5II. The practice of physic at this time was largely conducted by the ignorant portion of the artisan class. Degrees, however, conferring the right to practice, were held in very high esteem by the people.

The progress of medical knowledge during the seventeenth century has been ably described by $\mathrm{Mc}$ Cauley, in vol. I, page 3 ro, of his History. "Medicine," he says, "which in France was still in abject bondage and afforded for Molière an inexhaustible subject of just ridicule, had in England become an experimental and progressive science, and every day made some new advance in defiance of Hypocrates and Galen. The attention of speculative men had for the first time been directed to the important subject of sanitary police."

To that period belong the chemical discoveries of Boyle, and the first botanical researches of Sloan. One after another, phantoms which had haunted the world through ages of darkness, fled before the light, and astrology and alchemy became jests. Upon research I find that in ancient times effective medical legislation and higher medical education progressed hand in hand. After extensive research I am unable to find that any court or legislative body in the British Isles or Continental Europe ever questioned the propriety of effective medical legislation.

It seems quite absurd that the propriety of regulating the practice of medicine should be questioned by any respectable portion of the profession of this day. My experience, however, teaches me that such opposition is quite pronounced with a few. Their principal reasons for such opposition lies in their misguided interpolations of the functions of a republican form of government, and an extreme conservatism in all matters pertaining to their chosen profession. Those of us who have been missionaries in this work of reform for some time have not infrequently found the representations of many of our reputable medical schools working arm in arm with the long-haired quack, in their endeavors to strangle the crudest forms of legislation. I make the broad assertion that practically the only opposition to effective medical legislation in this country comes from the profession itself, and that this opposition comes principally from the representatives of the seventy-nine medical schools of the United States, that continue to graduate men upon the courses of lectures of twenty weeks' duration each. It is unnecessary that I should point to New York, Illinois or Minnesota to verify my assertion. It is certainly the duty of the chosen representatives of the people, the legislature, to protect an ignorant and credulous public from empiricism and imperfectly educated medical men and women. No profession or vocation is allied so closely to his material interests; yet, in the selection of a medical adviser the community, not infrequently, cares but little for a man's actual medical ability. The masses of the community, in the selection of a family physician, make it upon personal grounds alone. Were one of us stricken by disease or accident in the streets of this city, we would probably obtain more skillful treatment at the average hospital than at a friend's house upon the most fashionable avenue. The propriety of the reg. ulation of the practice of law is never questioned. Every State in the Union regulates the practice of law with an iron hand. The attorney that defrauds his client has his license revoked, and there is no complaint thereat. Ecclesiastical councils regulate the actions and utterances of their clergy by canons quite as strict as in the days of Martin Luther, and the courts endorse their findings with the precedent of the common law as their argument. In the cities, the construction of our homes, even, is superintended by the sanitary police.

It is, however, ordained that in our profession, the noblest of them all, we shall be left to a competition that is intolerable to an educated man. I find upon examination of the literature of medical legislation, that the United States is the only civilized country that is devoid of restrictions regulating the practice of medicine. There are at the present time, however, about thirty States with so called medical prac- 